\title{
Importância da implantação do plano de gerenciamento de resíduos da construção civil e de demolição no Município de João Pessoa (Estado da Paraíba, Nordeste do Brasil)
}

Natália Marques de Almeida Lima Miranda ${ }^{1}$, Virgínia Falcão de Oliveira Lima ${ }^{2}$, Josemary M. Freire Rodrigues de C. Rocha ${ }^{3}$, Raquel de Lourdes de Miranda e Silva Carmona ${ }^{4}$, Cícero Sousa Lacerda ${ }^{3}$, Érika Marques de Almeida Lima ${ }^{3}$, Patrícia Tavares de Lima $^{3}$, Hercílio de Medeiros Sousa ${ }^{3}$, Jaíze Costa do Nascimento ${ }^{3}$ e João Carlos de Miranda e Silva ${ }^{5}$

\footnotetext{
${ }^{1}$ Instituto do Patrimônio Histórico e Artístico da Paraíba - IPHAEP. Av. João Machado, 348. Jaguaribe. João Pessoa-PB, Brasil. E-mail: nataliamarques.iphaep@gmail.com.

${ }^{2}$ Faculdade Internacional da Paraíba - FPB. Av. Monsenhor Walfredo Leal, 512. Tambiá. João Pessoa-PB, Brasil (58020-540).

${ }^{3}$ Instituto de Ensino Superior da Paraíba - IESP. Estrada de Cabedelo, BR 230, km 14, s/n. Morada Nova. Cabedelo-PB, Brasil (CEP 58109-303).

${ }^{4}$ Universidade Federal da Paraíba. Programa de Pós-Graduação em Ciências das Religiões. Centro de Educação. Universidade Federal da Paraíba. Campus I. João Pessoa-PB, Brasil (CEP 58051-900).

${ }^{5}$ Superintendência de Administração de Meio Ambiente - SUDEMA. Av. Monsenhor Walfredo Leal, 181. Tambiá. João Pessoa-PB, Brasil (CEP 58020-540).
}

Resumo. 0 presente artigo trata sobre a importância do manejo, que inclui o descarte dos resíduos sólidos da construção civil e demolição (RCD). Além de deixar evidente a necessidade da Educação Ambiental para a compreensão da multifatorialidade que envolve esse contexto. Assim, tornou-se necessário abordar a legislação brasileira, as normativas pertinentes à defesa do meio ambiente, no que diz respeito ao tratamento dado aos RCD's de maneira geral e o que aponta a Prefeitura Municipal de João Pessoa, capital paraibana. Para dar corpo a este estudo, partiu-se em busca de uma investigação qualitativa de natureza bibliográfica que, dentre outras questões, elencou o processo de tratamento dado ao descarte proveniente deste setor no contexto local.

Palavras-chave: Educação ambiental; Gestão de resíduos sólidos; Resíduos da construção e demolição.

Abstract. Implementation of the construction and demolition waste management plan in the Municipality of João Pessoa (Paraíba State, Northeast Brazil). This paper deals with the importance of management, which includes solid waste disposal
Recebido:

20/07/2019

Aceito:

$31 / 08 / 2019$

Disponível on line:

$31 / 08 / 2019$

Publicado:

31/08/2019

Acesso aberto

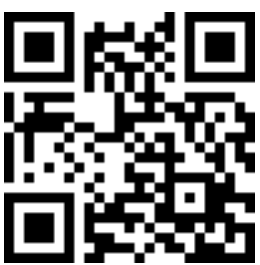


from construction and demolition. In addition to highlighting the need for Environmental Education to understand the multifactoriality that surrounds this context. Thus, it became necessary to address the Brazilian legislation, the pertinent norms regarding the protection of the environment, regarding the treatment given to the CDW's in general and what the Municipal Government of João Pessoa, Capital of Paraíba State, points out. To embody this study, we set out to seek a qualitative research of bibliographic nature that, among other issues, listed the treatment process given to the disposal from this sector in the local context.

Keywords: Environmental Education; Solid waste management; Construction and demolition wastes.

\section{Introdução}

Os resíduos da construção civil e demolição (RCD) são todos os resíduos provenientes de construções, reformas, reparos ou demolições. Por ser produzido em um setor no qual convivem diferentes técnicas e metodologias de produção, cujo controle da qualidade do processo produtivo é recente, as características são relevantes, no sentido de diagnosticar e contribuir com a melhor metodologia e suas ferramentas de manejo. Assim, a composição e quantidade produzidas dependem diretamente do estágio de desenvolvimento da indústria de construção local e da fase da obra (fundação, estrutura, alvenaria ou acabamento). Para Zordan (1998) as

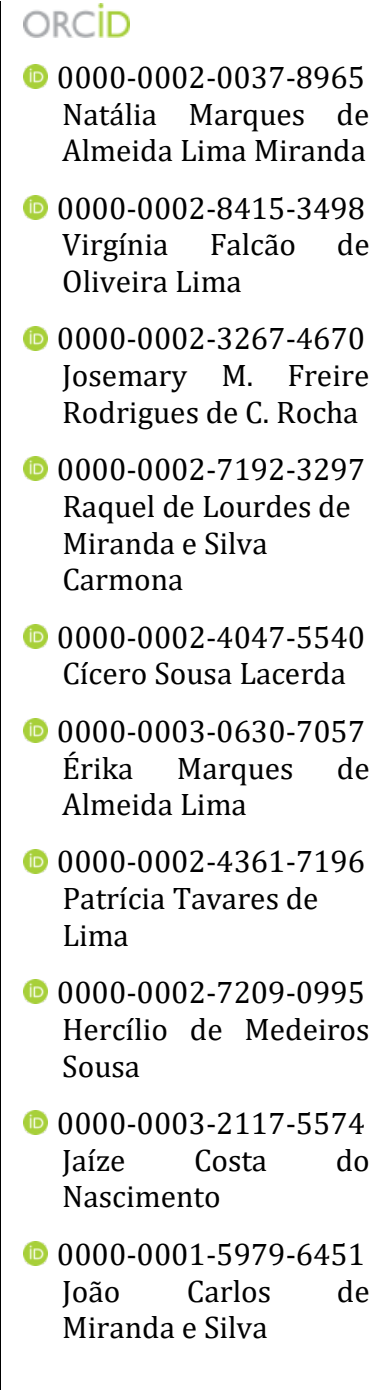

características do resíduo analisado dependem de parâmetros específicos do local onde o mesmo foi gerado. 0 entulho é sólido e o mais heterogêneo dentre os resíduos, podendo apresentar-se em tamanho e formas geométricas conhecidas dos materiais de construção, mas em muitas ocasiões ele aparece em formatos e dimensões irregulares: pedaços de madeiras, argamassas, concretos, plásticos e metais (Zordan, 1998).

Uma ferramenta que auxilia a diminuição de geração e descarte inadequado de resíduos, é o princípio dos 3 R's - reduzir, reutilizar e reciclar. Os pilares dessa ferramenta foram discutidos na Conferência da Terra, em 1992 - ECO 92, da qual resultou a Agenda 21 - Global, que em sua Seção II - 
Conservação e Gerenciamento dos Recursos para o Desenvolvimento, trata, dentre outras coisas, do manejo dos resíduos sólidos (Brasil, 1992). Medidas que dinamizadas e ampliadas, continuam adotadas até hoje. 0 termo Reduzir está associado a adoção de alternativas de menor consumo de matérias primas e diminuição de desperdício, esses resultados são facilmente obtidos se associados a um projeto eficiente de gestão. Já a reutilização é quando o resíduo já gerado é reaplicado sem melhoramento ou transformação. 0 terceiro pilar dos 3 R's é a reciclagem, que consiste na transformação de resíduos que não puderam ser reutilizados, em matérias primas ou até novos produtos.

Praticamente todas as atividades desenvolvidas no setor da construção civil são geradoras de entulho, sendo que, no processo construtivo, $\mathrm{o}$ alto índice de perdas do setor é a principal causa do entulho gerado (Baptista Júnior e Romanel, 2013). Embora nem toda perda se transforme efetivamente em resíduo, pois uma parte é reutilizada na própria obra, como por exemplo, o solo retirado durante a etapa de fundação, poderá ser reutilizado como aterro e a sobra de concreto podendo ser aproveitada em calçadas e rampas da própria construção.

Existem muitos aspectos que interferem na quantidade, nas características e na composição do resíduo. Em um mesmo país, em diferentes regiões pode ocorrer a variação da composição dos entulhos gerados. Batista Júnior e Romanel (2013), destacam que entre esses aspectos, a multifatorialidade deve ser considerada. Portanto, o nível de desenvolvimento da indústria da construção local; a qualidade da mão de obra disponível; as técnicas de construção e demolição empregadas; a utilização de programas de qualidade e redução de perdas; a adoção de processos de reciclagem e reutilização no canteiro; os tipos de materiais predominantes e/ou disponíveis na região; o desenvolvimento de obras especiais na região (metrô, esgotamento sanitário, restauração de centros históricos, entre outros); desenvolvimento econômico da região; o aumento do número de novas construções, são considerados fatores agravantes ou atenuantes, a depender do uso consciente que cada processo adota.

\section{Política dos Resíduos Sólidos e a resolução do Conselho Nacional do Meio Ambiente (CONAMA)}

A Resolução CONAMA no $307 / 2002$, entrou em vigor a partir de janeiro de 2003, criando instrumentos para a superação dos problemas que vem ocorrendo, definindo responsabilidades e deveres para o novo sistema de gestão dos resíduos. Também impõe aos geradores a obrigatoriedade da redução, reutilização e reciclagem, quando, prioritariamente, a geração dos resíduos não puder ser evitada (Brasil, 2002). Nesse sentido, considerando a diversidade das características desses geradores, a resolução define diretrizes para que os municípios e o Distrito Federal desenvolvam e implantem políticas específicas de gestão local, na forma de Planos Integrados de Gerenciamento, nos quais expressem as responsabilidades desses geradores diversificados segundo as características de cada realidade.

Obedecendo às diretrizes gerais da resolução, cabe aos municípios assumirem a solução para o problema dos pequenos volumes, quase sempre mal dispostos, bem como o disciplinamento da ação dos agentes envolvidos com os grandes volumes de resíduos. A mesma resolução classifica os resíduos de construção civil em quatro classes:

I - Classe A - são os resíduos reutilizáveis ou recicláveis como agregados, tais como: 
a) de construção, demolição, reformas e reparos de pavimentação e de outras obras de infraestrutura, inclusive solos provenientes de terraplanagem;

b) de construção, demolição, reformas e reparos de edificações: componentes cerâmicos (tijolos, blocos, telhas, placas de revestimento etc.), argamassa $\mathrm{e}$ concreto;

c) de processo de fabricação e/ou demolição de peças prémoldadas em concreto (blocos, tubos, meio-fio etc.) produzidas nos canteiros de obras;

II - Classe B - são os resíduos recicláveis para outras destinações, tais como: plásticos, papel/papelão, metais, vidros, madeiras e gesso;

III - Classe C - são os resíduos para os quais não foram desenvolvidas tecnologias ou aplicações economicamente viáveis que permitam a sua reciclagem/recuperação;

IV - Classe D: são resíduos perigosos oriundos do processo de construção, tais como tintas, solventes, óleos e outros ou aqueles contaminados ou prejudiciais à saúde, oriundos de demolições, reformas e reparos de clínicas radiológicas, instalações industriais, e outros bem como telhas e demais objetos e materiais que contenham amianto ou outros produtos nocivos à saúde.

A referida resolução ainda determina que os municípios deverão elaborar o Plano Municipal de Gestão de Resíduos de Construção Civil. Algumas alterações foram feitas desde sua publicação, a Resolução CONAMA no 431/2011 (Brasil, 2011), alterando a classificação do gesso que era inserido a classe C (resíduo para o qual não foi desenvolvida tecnologia que permita sua reciclagem ou recuperação) para classe $B$ (resíduo reciclável para finalidade diferente do agregado) e a Resolução CONAMA no 448/2012 (Brasil, 2012) altera a redação de uns artigos e revoga outros. Nesse contexto, ainda a instituição da Lei no $12.305 / 2010$ (Brasil, 2010), a Política Nacional dos Resíduos Sólidos prioriza a não geração, redução, reutilização, reciclagem, tratamento dos resíduos sólidos e disposição final ambientalmente adequada dos rejeitos (Batista Júnior e Romanel, 2013).

No Município de João Pessoa, capital paraibana, a Lei Municipal no 11.176/2007, apresenta um sistema de gestão sustentável dos resíduos da construção e demolição através da instituição do plano de gerenciamento dos RCD que incorpora o programa municipal de gerenciamento e os projetos de gerenciamento (João Pessoa, 2007). Portanto esse projeto de gerenciamento deve ser elaborado pelos geradores e se trata de um conjunto de medidas preparadas individualmente para cada empreendimento que deverá apresentar a caracterização dos resíduos e procedimentos que deverão ser adotados para sua minimização e para o manejo correto nas etapas de triagem, acondicionamento, transporte e destinação final que deverá estar em consonância a Resolução CONAMA no $307 / 2002$.

\section{PGRCCD e a gestão do canteiro de obras}

Diante do que regem as normativas, é necessário ter atenção ao Plano de Gerenciamento de Resíduos da Construção e Demolição (PGRCCD), um documento que identifica a quantidade de resíduos gerados provenientes de construções, reformas, reparos, demolições de obras e da preparação e escavação de terrenos. Seu objetivo é estabelecer procedimentos necessários para o manuseio e destinação final adequados dos resíduos, frequentemente chamados de entulhos de obras. 0 PGRCCD indica a destinação conforme a classificação de resíduos definida pela Resolução CONAMA no 307/2002. Para Batista Júnior e Romanel (2013), em conformidade com o que preconiza a 
legislação brasileira, todo gerador é responsável pelo gerenciamento dos seus resíduos, segregando-os, preferencialmente, na origem, utilizando-se do transporte regular e adequado, além de providenciar a disposição final em locais devidamente licenciados ou autorizados pelo município.

A preocupação com a não geração dos resíduos está presente na implantação e consolidação do programa de gestão de resíduos. Os benefícios almejados com a implantação PGRCCD são organização e limpeza do canteiro, triagem de resíduos, impedindo sua mistura com insumos; reaproveitamento de resíduos antes de descartá-los; quantificação e qualificação dos resíduos descartados, possibilitando a identificação de possíveis focos de desperdício de materiais.

A gestão desses resíduos no canteiro de obras está associada aos inúmeros fatores que contribuem para a sua geração, seja pela falta de definições e detalhamentos satisfatórios nos projetos, ausência de precisão nos memoriais descritivos, baixa qualidade dos materiais utilizados, falta de qualificação da mão de obra, o manejo, transporte ou armazenamento inadequado dos materiais, ineficiência dos mecanismos de controle durante a execução da obra, escolha da técnica inadequada para construção ou demolição, e deficiência nos processos de reutilização e reciclagem no canteiro.

As condições para uma boa administração de resíduos devem seguir um roteiro pré-estabelecido o acondicionamento inicial, o transporte interno e o acondicionamento final. Sem esquecer a possibilidade de reutilização ou reciclagem de alguns tipos de resíduos dentro dos canteiros. Sendo a primeira etapa para o gerenciamento de resíduos na obra é a descrição de ações de sensibilização, mobilização e educação socioambiental para os colaboradores da construção, visando a atingir as metas de minimização, reutilização e segregação dos resíduos sólidos na origem, bem como seus corretos acondicionamentos, armazenamento e transporte.

\section{Educação ambiental e o manejo dos RCD'S}

Ainda que o foco desse estudo não seja a educação ambiental em si, mas é praticamente impossível não associar o descarte de resíduos com tal questão disciplinar. Sobretudo, porque a Educação Ambiental torna-se relevante para que os colaboradores sejam treinados e se tornem conhecedores da classificação dos resíduos, não só para executarem satisfatoriamente a segregação dos mesmos como também pela importância ambiental que essa tarefa representa. Neste sentido, Rodrigues (2015) estabelece uma breve contextualização acerca do termo, assinalando que se trata de um tema discutido nos meios acadêmicos, reforçado pela já epigrafada Rio 92, mas que se remete a segunda metade do século XIX; com a publicação do livro de George Perkin Marsh, em 1864), acerca das agressões praticadas pelo ser humano à natureza.

Data ainda do século XIX, a carta do Chefe Seatlle ao presidente Pierce, dos Estados Unidos, que "é considerado como um dos mais profundos pronunciamentos sobre a defesa do meio ambiente, sendo de uma atualidade indiscutível. Isto porque chama a atenção para a falta de respeito e de cuidado com a terra e, consequentemente, com o equilíbrio ecológico (Catani, 1988). Para Dias (1992), a partir da década de 1970, do século seguinte é se tem uso a expressão environmental education (educação ambiental) nos Estados Unidos, que traz um inovador pensamento de preservação ambiental, ao aprovar a Lei sobre Educação Ambiental. No Brasil, desde o surgimento na década de 1970, com a instituição da primeira Secretaria Especial do Meio Ambiente (Sema), o processo de conscientização vem crescendo e 
consolidando a ideia da necessidade de uma consciência ambiental (Dias, 1992; Carvalho, 2006 Rodrigues, 2015).

Nas décadas seguintes, sobretudo com a realização da Eco 92, no Rio de Janeiro, o Brasil vai alavancar o entendimento para a instauração de medidas que lançam um olhar mais apurado para essa educação ambienta e em 1994 é aprovado o Programa Nacional de Educação Ambiental (Pronea), cujo objetivo é sedimentar políticas que corroboração com o processo de Educação Ambiental (Rodrigues, 2015). Portanto, é essa educação que traz uma consciência crítica acerca dos resíduos, que tem a sua presença como fundamental no canteiro de obras da construção civil. Isto posto, por considerar que o manejo de resíduos, no sentido de cuidar, tratar, descartar, deve ser realizado de maneira responsável obedecendo aos parâmetros de uma educação ambiental, preocupada com o ambiente, de maneira holística, enxergando a sua obra e o seu entorno.

Em relação ao manejo de resíduos na construção civil, pode-se afirmar que há uma relação direta entre os fluxos, os estoques dos materiais e equipamentos no canteiro e a geração de resíduos. Devido a isto se ressalta o acondicionamento adequado dos materiais, obedecendo aos critérios básicos de: classificação; frequência de utilização; empilhamento máximo; distanciamento entre as fileiras; alinhamento das pilhas; distanciamento do solo; separação, isolamento ou envolvimento por ripas, papelão, isopor etc. (no caso de louças, vidros e outros materiais delicados, passíveis de riscos, trincas e quebras pela simples fricção); preservação da limpeza e proteção contra a umidade do local (objetivando principalmente a conservação dos ensacados).

Por fim, de acordo com o art. 9으, da Resolução CONAMA no 448/2012, os Planos de Gerenciamento de Resíduos da Construção Civil deverão contemplar as seguintes etapas: caracterização: 0 gerador deve identificar e quantificar os resíduos; triagem: deve ser realizada pelo gerador na origem, ou nas áreas de destinação licenciadas para essa finalidade, respeitadas as classes de resíduos já citadas anteriormente; acondicionamento: o gerador deve garantir o confinamento dos resíduos após a geração até a etapa de transporte, assegurando as condições de reutilização e de reciclagem; transporte que deverá ser realizado em conformidade com as normas técnicas vigentes para o transporte de resíduos e cuja destinação deverá ser prevista de acordo com o estabelecido na Resolução (Brasil, 2012). Nesse sentido, a redução da geração de resíduos implica também na diminuição dos custos de transporte externo e destinação final. Segundo a Resolução CONAMA no 448/2012, os resíduos da construção civil, após triagem, deverão ser destinados como indicado na Tabela 1.

A coleta e remoção dos resíduos do canteiro devem ser feitas conciliando alguns fatores, sendo: compatibilização com a forma de acondicionamento final dos resíduos na obra; minimização dos custos de coleta e remoção; possibilidade de valorização dos resíduos; adequação dos equipamentos utilizados para coleta e remoção aos padrões definidos em legislação.

Quando existir resíduos provenientes da atividade não construtiva, estes também serão transportados, portanto, de forma correta a não poluir o meio ambiente e proporcionando aos colaboradores um ambiente higiênico, no local de trabalho. Por exemplo: restos de alimentos, embalagens, copos descartáveis, papéis sujos utilizados no refeitório, nas instalações sanitárias e áreas de vivência devem ser transportados através de veículos utilizados na coleta pública dos resíduos domiciliares, obedecendo aos limites estabelecidos pela legislação municipal competente. 
Tabela 1. Destinação dos RCD’s segregados por classe, segundo Resolução CONAMA no 448/2012.

\begin{tabular}{|l|l|}
\hline A & $\begin{array}{l}\text { DESTINAÇÃO } \\
\text { aterro de resíduos. }\end{array}$ \\
\hline B & $\begin{array}{l}\text { Deverão ser reutilizados, reciclados ou encaminhados a áreas de armazenamento } \\
\text { temporário, sendo dispostos de modo a permitir a sua utilização ou reciclagem futura. }\end{array}$ \\
\hline C & $\begin{array}{l}\text { Deverão ser armazenados, transportados e destinados em conformidade com as } \\
\text { normas técnicas específicas. }\end{array}$ \\
\hline Deverão ser armazenados, transportados e destinados em conformidade com as \\
normas técnicas específicas.
\end{tabular}

Independentemente do tipo de material a ser transportado, a caçamba deverá sempre permanecer coberta com lona, e a mesma estar adequadamente presa evitando que os resíduos armazenados venham a sujar a via pública durante a operação de transporte. Alguns desses materiais descartados são considerados perigosos, consequentemente, devem ser separados dos demais RCD's para que seja dada uma destinação específica. Entre os materiais perigosos, pertencentes a Classe D, podem ser incluídos: materiais para jardinagem e tratamento de animais, repelentes, inseticidas e pesticidas; produtos para motores: óleos lubrificantes, fluidos de freio e baterias; outros itens como restos de tintas, pilhas, frascos de aerossóis e lâmpadas fluorescentes.

Os fabricantes e os importadores desses produtos deverão dar destinação ambientalmente adequada aos produtos e às embalagens, na forma estabelecida pelo órgão competente. 0 registro dos resíduos transportados é feito através da CTR (Controle de Transporte de Resíduos), que é um formulário, que visa atender as NBR 15.112, NBR 15.112 e 15.114 (ABNT, 2004) e deverá ser emitido em três vias (1 $1^{\text {a }}$ via - para gerador; $2^{\mathrm{a}}$ via - para o transportador; $3^{\mathrm{a}}$ via - para o destinatário), que irão acompanhar o veículo de transporte dos resíduos durante o deslocamento do mesmo, em seguida devem ser arquivados juntamente com demais documentos necessários à comprovação da correta triagem, transporte e destinação dos resíduos gerados. Cada coleta implicará a emissão de um documento CTR, que registrará a destinação dos resíduos coletados, contendo as seguintes informações: dados do gerador; resíduos destinados, com volume ou peso e unidades correspondentes; dados do transportador; dados do destinatário; assinatura e carimbos (gerador, transportador e destinatário).

A Lei Municipal no 11.176/2007 aborda que os grandes volumes de resíduos da construção civil e demolição, superiores a $2,5 \mathrm{~m}^{3}$ (dois metros e meio cúbicos) por descarga, devem ser destinados à rede de área para recepção de grandes volumes, onde devem ser objeto de triagem e destinação adequada. As soluções para a destinação dos resíduos devem combinar compromisso ambiental e viabilidade econômica, garantindo a sustentabilidade $\mathrm{e}$ as condições para a reprodução da metodologia utilizada pelos construtores (Tabela 2). 
Tabela 2. Soluções de destinação para os RCD’s, Resolução CONAMA no 448/2012.

\begin{tabular}{|c|c|c|}
\hline TIPOS DE RESÍDUOS & CUIDADOS NA RECICLAGEM & DESTINAÇÃO \\
\hline $\begin{array}{l}\text { Blocos de concreto, } \\
\text { blocos cerâmicos e } \\
\text { argamassas }\end{array}$ & $\begin{array}{l}\text { Podem ser reciclados para o uso em } \\
\text { pavimentos e concretagem sem } \\
\text { função estrutural }\end{array}$ & $\begin{array}{l}\text { Áreas para reciclagem ou } \\
\text { aterros de RCD licenciados } \\
\text { pelos órgãos competentes }\end{array}$ \\
\hline Madeira & $\begin{array}{l}\text { Podem ser reciclados para o uso em } \\
\text { caldeira, porém a serragem deve ser } \\
\text { separada da madeira }\end{array}$ & $\begin{array}{l}\text { Atividades econômicas que } \\
\text { utilizam a madeira como } \\
\text { combustível em fornos e/ou } \\
\text { caldeiras }\end{array}$ \\
\hline Plásticos & - & $\begin{array}{l}\text { Cooperativas ou Associações de } \\
\text { coleta seletiva. }\end{array}$ \\
\hline Papelão & Proteger de intempéries & $\begin{array}{l}\text { Cooperativas ou Associações de } \\
\text { coleta seletiva }\end{array}$ \\
\hline Metal & - & $\begin{array}{l}\text { Cooperativas ou Associações de } \\
\text { coleta seletiva. }\end{array}$ \\
\hline Serragem & Ensacar e proteger de intempéries & $\begin{array}{l}\text { Superfícies com presença de } \\
\text { óleo, contribuindo para } \\
\text { absorção }\end{array}$ \\
\hline $\begin{array}{l}\text { Gesso em placas } \\
\text { acartonadas }\end{array}$ & Proteger de intempéries & Empresas de reciclagem \\
\hline $\begin{array}{l}\text { Gesso de } \\
\text { revestimentos }\end{array}$ & Proteger de intempéries & $\begin{array}{l}\text { Aproveitamento pela própria } \\
\text { indústria de gesso ou por } \\
\text { empresas de reciclagem }\end{array}$ \\
\hline Solo & $\begin{array}{l}\text { Primeiramente deve-se examinar a } \\
\text { caracterização. }\end{array}$ & $\begin{array}{l}\text { Não estando contaminados, } \\
\text { destina-se a áreas de } \\
\text { aterramento. }\end{array}$ \\
\hline Telas de proteção & - & $\begin{array}{l}\text { Deverão ser reaproveitadas nas } \\
\text { próximas obras da construtora. }\end{array}$ \\
\hline EPS & $\begin{array}{l}\text { Armazenar adequadamente e } \\
\text { proteger de intempéries }\end{array}$ & $\begin{array}{l}\text { Cooperativas ou Associações de } \\
\text { coleta seletiva. }\end{array}$ \\
\hline
\end{tabular}

O Município de João Pessoa, possui uma população de 811.598 habitantes, segundo dados do IBGE (2010), e devido ao crescente processo de urbanização apresenta elevado índice de geração RCD. Por isso no ano de 2007 foi instalada, no município, uma usina de reciclagem denominada Usina de Beneficiamento dos Resíduos de Construção (USIBEN). A USIBEN está capacitada para processar e reinserir no ciclo produtivo da construção civil os resíduos da classe " $A$ ", ou seja, os resíduos reutilizáveis ou recicláveis como agregados: componentes cerâmicos (tijolos, blocos, telhas, placas de revestimento etc.), argamassa e concreto; resíduos de peças prémoldadas em concreto (blocos, tubos, meios-fios etc.) produzidas nos canteiros de obra.

\section{Considerações finais}

Os RCD's são uma das principais problemáticas econômicas, sociais e ambientais enfrentadas por muitas cidades brasileiras. 0 Plano de Gerenciamento de Resíduos da Construção e Demolição (PGRCCD), quando elaborado corretamente $\mathrm{e}$ implantado de modo satisfatório, atendendo a tudo que nele consta, ocasiona benefícios para o meio ambiente, com a diminuição dos impactos causados pelas atividades construtivas; para o poder público, com o melhor aproveitamento do imposto 
destinado ao recolhimento do lixo já que o mesmo também é empregado para retiradas de resíduos dispostos em locais inadequados; e também para o construtor, pois com a antecipação da geração de resíduos poderá ser feito um melhor planejamento da obra evitando assim o desperdício.

Para que o volume de resíduos gerados seja minimizado é necessário que haja uma integração entre todos os órgãos envolvidos no setor da construção civil, sendo também necessária a definição de um conjunto de ações, tais como: campanhas de conscientização da população, implantação e incentivo da coleta seletiva nos canteiros de obras. É importante a obrigatoriedade dos Planos de Gerenciamento não só em obras particulares, como vem ocorrendo em nosso município, mas principalmente em obras do governo ou as obras financiadas por bancos federais.

Considerando a evolução das técnicas de reciclagem dos resíduos da construção e demolição, é cedo para afirmar com absoluta convicção que a reciclagem tenha se tornado uma ideia amplamente difundida no setor construtivo em João Pessoa, sendo ainda um dos principais desafios que a construção civil de nossa cidade deve enfrentar nos próximos anos. A Prefeitura de João Pessoa teve uma ótima iniciativa com a Implantação da USIBEN, principalmente se comparada a outras cidades, inclusive nordestinas, que não possuem nenhum plano direcionado a destinação de seus resíduos sólidos. Neste contexto, as empresas de construção civil somente sairão da inércia quando sofrerem fiscalizações e taxações. Sendo necessária a implantação de uma legislação ainda mais rigorosa, com a diminuição dos custos para descarte de resíduos e aquisição de matéria prima para uma efetiva redução dos impactos ambientais.

De forma geral, foi possível concluir que a questão ambiental, por si só, não é motivadora para a adoção de novos procedimentos; que a Resolução CONAMA no 307/2002 do ainda está produzindo os efeitos desejados; e que a reciclagem de resíduos da classe " $\mathrm{A}$ " no canteiro de obras é uma atividade viável tecnicamente e economicamente, ressaltando a importância de um rigoroso controle de qualidade dos materiais produzidos com RCD para evitar o surgimento de patologias nas construções. Também é válido e nunca suficiente assinalar que a educação ambiental é fundamental para o manejo do descarte. Seja em qualquer setor, em qualquer situação ou lugar.

\section{Conflito de interesses}

Os autores declaram não haver conflitos de interesses.

\section{Referências}

ABNT - Associação Brasileira de Normas Técnicas. ABNT NBR 15.112:2004 Resíduos da construção civil e resíduos volumosos - Áreas de transbordo e triagem - Diretrizes para projeto, implantação e operação. Rio de Janeiro: ABNT, 2004.

ABNT - Associação Brasileira de Normas Técnicas. ABNT NBR 15.113:2004 Resíduos sólidos da construção civil e resíduos inertes - Aterros - Diretrizes para projeto, implantação e operação. Rio de Janeiro: ABNT, 2004.

ABNT - Associação Brasileira de Normas Técnicas. ABNT NBR 15.114:2004 Resíduos sólidos da Construção civil Áreas de reciclagem - Diretrizes para projeto, implantação e operação. Rio de Janeiro: ABNT, 2004.

Baptista Junior, J. V.; Romanel, C. Sustentabilidade na indústria da construção: uma logística para reciclagem dos resíduos de pequenas obras. urbe. Revista Brasileira de Gestão Urbana, v. 5, n. 2, p. 27-37, 2013. https://doi.org/10.7213/urbe.05.002.SE02

Brasil. Conselho Nacional do Meio Ambiente. Resolução CONAMA no 307, de 5 de julho de 2002. Estabelece diretrizes, critérios e procedimentos para a gestão dos resíduos da 
construção civil. Disponível em: <https://www.mma.gov.br/estruturas/a3p/ _arquivos/36_09102008030504.pdf>. Acesso em: 11 out. 2018.

Brasil. Conselho Nacional do Meio Ambiente. Resolução CONAMA no 431, de 24 de maio de 2011. Altera o art. $3^{\circ}$ da Resolução $\mathrm{n}^{\circ}$ 307, de 5 de julho de 2002, do Conselho Nacional do Meio Ambiente-CONAMA, estabelecendo nova classificação para o gesso. Disponível em: <http://www2.mma. gov.br/port/conama/legiabre.cfm?codlegi=6 49>. Acesso em: 11 out. 2018.

Brasil. Conselho Nacional do Meio Ambiente. Resolução CONAMA no 448, de 18 de

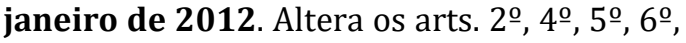
8o, 9o, 10 e 11 da Resolução no 307, de 5 de julho de 2002, do Conselho Nacional do Meio Ambiente-CONAMA. Disponível em: <http://www2.mma.gov.br/port/conama/le giabre.cfm? codlegi=672>. Acesso em: 11 out. 2018.

Brasil. Lei no 12.305, de 2 de agosto de 2010. Institui a Política Nacional de Resíduos Sólidos; altera a Lei $\mathrm{n}^{-}$9.605, de 12 de fevereiro de 1998; e dá outras providências. Disponível em: <http://www.planalto. gov.br/ccivil_03/_ato2007-2010/2010/lei/ 112305.htm>. Acesso em: 11 out. 2018.

Brasil. Ministério do Meio Ambiente. Agenda 21 - Global. 1992. Disponível em: <https://www.mma.gov.br/responsabilidade -socioambiental/agenda-21/agenda-21global.html>. Acesso: 26 nov. 2018.

Carvalho, I. C. M. Educação Ambiental: a formação do sujeito ecológico. 2. ed. São Paulo: Cortez, 2006.
Catani, A. M. Preservação do meio ambiente: manifesto do Chefe Seattle ao presidente dos EUA. Revista de Administração de Empresas, $\quad$ v. 28, $\quad$ n. 1, p. 58, 1988. https://doi.org/10.1590/S0034-759019880 00100010

Dias, G. F. Educação Ambiental: princípios e prática. São Paulo: Gaia, 1992.

IBGE - Instituto Brasileiro de Geografia e Estatística. 2010. Disponível em: <http://www.ibge.gov.br/>. Acesso em: 02 abr. 2018.

João Pessoa. Lei no 11.176, de 10 de outubro de 2007. Resíduos da construção civil. Disponível em: <http://www.joao pessoa.pb.gov.br/legislacao/lei-no-11-176de-10-de-outubro-de-2007-sistema-degestao-sustentavel-de-residuos/>. Acesso em: 22 maio 2019.

Rodrigues, D. C. Proposição de um plano de gerenciamento de resíduos sólidos para o Centro Integrado de Operação e Manutenção da CASAN (CIOM). Florianópolis: UFSC, 2015. (Trabalho de conclusão de curso).

Zordan, S. E.; Paulon, V. A. A utilização do entulho como agregado para o concreto. Anais do Encontro Nacional de Tecnologia do Ambiente Construídos, p. 923-932, 1998. 